\section{HEALTHlink is calling for new members!}

Doctors of the World UK (Medecins du Monde UK) invites you to join HEALTHlink, a national network working to break down the barriers to free healthcare access for vulnerable groups.

HEALTHlink

- provides information about how to register a patient;

- briefs members on developments in health policy;

- brings together advocacy partners;

- provides forum for referral exchanges;

- shares information, best practice and peer-to-peer support;

- offers a dynamic platform to launch campaigns; and

- compiles key research and case studies on access to health care for marginalised groups.

\section{Your help is needed}

Because Mirko, aged 3, couldn't find a doctor who could treat his high fever since his family lacked a proof of address.

\section{Because Priscilla, a torture survivor from Uganda could not register with a GP to get the life-saving HIV treatment she needs, since her asylum application is being processed.}

\section{Because health is a human right, and we can protect it together.}

By joining you will become a powerful force, ensuring that the community's most vulnerable get the health care they need.

To learn more about HEALTHlink visit: http://www.dowhealthlink.org.uk or email: healthlink@doctorsoftheworld.org.uk

DOI: 10.3399/bjgp10X509739

\title{
The politics of behaviour
}

In his foreword to the policy green paper $A$ Healthier Nation, David Cameron proposes an 'altogether different' and 'entirely new' approach to public health compared with that pursued by the Labour government over the past decade. ${ }^{1}$ But his emphasis on the need to 'encourage people to make the right choices about what they eat, drink, and do in their leisure time' sounds like the same old public health sermon that has been preached by different governments over the past 40 years.

So, what is new and different? The central Tory theme is that policy will be guided by "cutting edge science and research' in the spheres of 'social psychology and behavioural economics'. The focus of government health policy on behaviour, in fact, already well established under Labour, reflects a wider transformation of the relationship between the state and the individual. The concept of behaviour is traditionally associated with children and animals. In place of the active subject of democratic citizenship, the behavioural approach assumes an individual who is the passive object of official policy. Instead of an independent agent playing an active role in society, the citizen is assumed to be ignorant and immature, requiring expert professional guidance. The self-determining individual is reduced to being the target of propaganda and manipulation. In their quest for novel behavioural gimmicks, the Tories have discovered American pop psychology books with snappy titles such as Connected and Nudge. ${ }^{2,3}$

The sole insight of Connected is that individuals are influenced by social factors: 'people do not have complete control over their own choices'. But the authors' 'social network' perspective treats individuals as passive objects who receive and transmit behaviours as though they were an infectious virus (although even the spread of the most infectious virus is influenced by specific individual and social factors). When it comes to practical measures, the authors fall back on Weight Watchers and Alcoholics Anonymous as a model. One of their few specific proposals is a 'creative alternative' to current vaccination policy based on immunising 'the acquaintances of randomly selected individuals'. This strategy is based on a mathematical model that suggests that 'acquaintances have more links and are more central to the network than are the randomly chosen people who named them'. But this model takes no account of the fact that most immunisations are aimed at a highly-selected population (mainly babies) who have a very limited circle of 'acquaintances'.

The concept of Nudge is that governments and employers should make self-conscious efforts to steer the choices of their citizens and workers in ways that improve their lives. The authors describe themselves as 'liberal paternalists' who reject bans and mandates in favour of 'weak, soft, nonintrusive' measures to create a 'choice architecture' that can 'influence people's behaviour in order to make their lives longer, healthier, and better'. The most familiar illustration of this approach is the fly incorporated into the ceramic of airport urinals, providing careless men with something to aim at - and thereby at a stroke reducing 'spillage' by $80 \%$.

The 'nudge' that appears most appealing to Tory public health strategists is the 'dollar a day' scheme in North Carolina, under which teenage girls receive $\$ 1$ for every day that they avoid becoming pregnant. A UK pilot offers pregnant women supermarket vouchers (excluding the sale of alcohol and tobacco) in return for abstinence from cigarettes: early results suggest that this is both cheaper and more effective than established 'smoking cessation' programmes. Such crass economic incentives are more likely to invite fraud than produce long-term changes in behaviour.

\section{REFERENCES}

1. Conservative Party. A healthier nation. Policy Green Paper No12, 2009.

2. Thaler R, Sunstein CR. Nudge: improving decisions about health, wealth and happiness. London: Penguin, 2009.

3. Christakis N, Fowler J. Connected: the amazing power of social networks and how they shape our lives. London: HarperPress, 2010.

DOI: 10.3399/bjgp10X509748 